\title{
Business Strategy, Market Orientation and Sales Growth in Hotel Industry of Ancient Cities in Sri Lanka
}

\author{
A.A.K.K. Jayawardhana ${ }^{*}$, S. De Silva ${ }^{1}$ and A.M.T.P. Athauda ${ }^{2}$ \\ Postgraduate Institute of Agriculture \\ University of Peradeniya \\ Sri Lanka
}

\begin{abstract}
The hotel industry is a decisive player in promoting tourism industry in any country. Incubating market centrism has received particular attention in the modern business world as a mode of reaping higher business performances. Improving the marketoriented philosophy and determining strategic orientation has become a critical management issue particularly in service driven firms. This paper attempts to determine the relationships between different types of business strategies, market orientation, and sales growth. The study was designed on the questions of whether different business strategies could influence on market orientation and then make influence on sales performances of hotels in the ancient cities in Sri Lanka. Data were collected from 43 hotels and both descriptive and inferential techniques were used to analyze the data. The results showed that the degree of market orientation differs significantly $(p<0.05)$ based on the business strategy of hotels and also market orientation has a significant positive relationship with sales performances. The majority of hotels' business strategy was to offer services at lower prices, which raises the question of the long-term sustainability of the industry. The study strongly suggests that the hotels should have a bold strategic move from offering low cost services to offering innovative services ahead of competitors and also maintain a higher degree of market orientation, through customer orientation, competitor orientation and interfunctional coordination.
\end{abstract}

Keywords: Business strategy, hotel industry, market orientation, sales growth

\section{INTRODUCTION}

Tourism has become a dynamic source of income generation for the economy of Sri Lanka. The up-ward trend of reaching a tolerant level of political and economic stability of the country after ending the 30 years long war has flashed a strong green light for the tourism industry to grow at a very fast rate as never in the history. Blessed with seven UNESCO named world heritage sites and being a richly bio-diversified land in spite of the smallness of the country, Sri Lanka is considered as one of the most attractive cultural and natural hotspots of the world. The hotel sector, which cannot be isolated from tourism, makes a decisive contribution for the development of the industry.

Department of Agricultural Extension, Faculty of Agriculture, University of Peradeniya, Sri Lanka

Department of Agribusiness Management, Faculty of Agriculture and Plantation Management,

Wayamba University of Sri Lanka

Corresponding aithor: kumuduaakk@gmail.com 
According to the Central Bank of Sri Lanka (2011), the hotel industry contributes to only around 2 percent to the country's Gross Domestic Product. The accommodation facilities prevailing in the hotel industry in Sri Lanka are dominated by tourist hotels which have accounted for 71 percent of the total accommodation facilities of 20,609 rooms that are rendered by the total lodging establishments registered with the Sri Lanka Tourism Development Authority (SLTDA) for 2011. According to RAM Ratings' report on the hotel sector 2011, foreigners do make up the majority of the patrons at Sri Lankan tourist hotels, contributing to nearly 70 percent of their total room nights. In the first half of 2010, holiday makers accounted for 79 percent of the country's tourist arrivals, underlining Sri Lanka's dependence on this segment that leads to highly vulnerable to global macroeconomic conditions and events. According to the same report, 17 percent of the tourist arrivals comprised of business travelers and the striking factor is that a better balance of the two sectors in this combination would enable hotels to smoothen the seasonality effect on their revenues as the number of holiday makers typically peak in November and December. The report further highlight that a tourist's average stay in a hotel is around 9 days in 2009 and this has remained relatively unchanged for the past few years.

Strategic perspective of a firm shapes the way that the firm voyage towards business excellence. Strategic orientation is a firm's strategic direction in creating proper behavior so as to achieve superior performance (Gatignon and Xuereb, 1997). Market and innovation orientations are two of the most important strategic orientations for firms to achieve longterm success (Berthon et al., 1999; Deshpande et al., 1993). The strategy-formulation is widely used to study the role of strategic orientation (Ginsberg and Venkataman, 1985; Homburg et al., 2002). Its basic proposition is that there is no universally beneficial strategic choice, and companies need to examine certain sets of organizational and environmental conditions to develop their own strategies. Accordingly, the formulation of strategies may be influenced by environmental factors, like market uncertainty, as well as by organizational characteristics, such as firm structure, culture, and systems (Ginsberg and Venkataman, 1985).

Market orientation (MO), the implementation of the marketing concept as a business philosophy, has received strong attention in the marketing literature. There appear to be several benefits of MO, although its role in improving business performance has been subjected to dispute for a long time (Laferty and Hult, 2001; Shapiro, 1988; Kohli and Jaworski, 1990). Narver and Slater (1994) stresses three behavioral elements which build market orientation namely Customer Orientation $(\mathrm{CuO})$, Competitor Orientation $(\mathrm{CoO})$, and Inter-Functional Coordination (IfC).

The market is constantly changing and the situation is marked by new competitors, unforeseen communication channels, globalization, but also by rapidly changing technology. According to Kotler (2003), the marketing concept is supported by four pillars: target market, customer needs (both are related to Customer Orientation-CuO), integrated marketing, and profitability. Narver and Slater (1990) define customer orientation as the sufficient understanding of one's target buyers to be able to create superior value for them continuously. The main problem of today's economy is its overcapacity - not products, but customers are in short supply while the available products and services are becoming more and more similar (Gabel, 1995).This process - already started in the 1970s when the transition from the seller's to the buyer's market took place - attention was no longer focused on the product but on customer preferences. 
Several researchers regard Competitor Orientation $(\mathrm{CoO})$ as an important part of what is referred to as market orientation (e.g. Han et al., 1998). The CoO comes along with organization's wider understanding of characteristics of the market where it is operating. An exclusive $\mathrm{CuO}$ may result in incomplete business strategy and action (Han et al.,1998) which suggests a balance of an organization's $\mathrm{CuO}$ and $\mathrm{CoO}$. However it is fair to believe that $\mathrm{CoO}$ entail sourcing information on competitors, competitors' activities and offerings, and market potentials. Along with Narver and Slater (1994) this study is done on the definition for CoO as a company's understanding of strengths, weaknesses, capabilities and strategies of key and potential competitors.

Inter-functional Coordination (IfC) refers to the degree of cooperation between the different functions/departments within the organization. It involves the coordination of company resources to create superior value for its customers through examining customer and competitor information. Extensive literature suggests three ways to achieve effective IfC. First is the alignment of the functional areas' performance objectives by focusing them on markets (e.g. customer satisfaction). Such market-based incentive systems motivate group interests, leading each function/department to participate whole heartedly in creating superior value for its customers (Wind and Robertson, 1983). Second, the creation of inter-functional dependency such that each area finds it advantages to cooperate closely with others increases the degree of coordination. Third, effective inter-functional coordination requires extreme sensitiveness and responsiveness to the perceptions and needs of all other departments.

Nerver and Slater (1994) identified a strong positive correlation between MO and sales growth. Business firms use different indicators such as gross margin, return on investment, return on equity, net sales growth, net profit growth to assess whether they have reached the desired level of performances within the defined time period. The Average Annual Sales Growth (AASG) rate was used in this study to measure the business performance, as many firms declined to divulge information on other indicators.

\begin{tabular}{|l|l|l|l|}
\hline $\begin{array}{l}\text { Business Strategy of } \\
\text { Hotels }\end{array}$ & $\begin{array}{l}\text { Market Orientation (MO) } \\
\text { Customer Orientation }(\mathrm{CuO}) \\
\text { Competitor Orientation (CoO) } \\
\text { Inter-functional Coordination (IfC) }\end{array}$ \\
\hline
\end{tabular}

\section{Fig. 1. Conceptual Framework}

The conceptual framework of the research is presented in Fig. 1. It is clear that strategic perspective of a hotel leads to varying degree of market sensitivity by making the hotel exposed to competitiveness. As an industry which is passing a decisive era, it is very important to evaluate whether Sri Lankan hotels are ready to accept the challenges of growth by being more customer oriented, competitor oriented and inter-functionally coordinated. Further, it is important to explore whether these three components have a relationship with sales performances. Hence, the research objectives here were to analyze the differences of degree of $\mathrm{CuO}, \mathrm{CoO}$ and IfC based on the different types of business strategies of hotels in ancient cities of Sri Lanka and to determine whether these three components collectively have an effect on sales growth of the hotels. 


\section{METHODOLOGY}

The working variables of the study are presented in Table 1 . The specific dimensions of the main concepts used are illustrated in this Table.

Table 1. Operationalization of the study

\begin{tabular}{|c|c|}
\hline Concept & Dimension/s of the Concept \\
\hline Business Strategy & $\begin{array}{l}\text { - introduce new products/services ahead of competitors } \\
\text { - offer higher quality products/services than competitors } \\
\text { - offer quick products/services. } \\
\text { - offer lower prices on comparable products/services of } \\
\text { competitors } \\
\text { - imitate competitors }\end{array}$ \\
\hline $\begin{array}{l}\text { Customer } \\
(\mathrm{CuO})\end{array}$ & $\begin{array}{l}\text { - business objectives are driven by the customer satisfaction } \\
\text { - takes all efforts to serve customer needs } \\
\text { - business strategies are driven by their belief on how they can } \\
\text { serve their customer's needs } \\
\text { - takes immense efforts in measuring the customer satisfaction } \\
\text { frequently and acts accordingly } \\
\text { - gives a closer attention for after sales service }\end{array}$ \\
\hline Competitor Orientation & $\begin{array}{l}\text { - concentration on competitors in making business decisions } \\
\text { - employees share information within firm regarding their } \\
\text { competitors' business strategies } \\
\text { - responds for the competitive actions of those threatened } \\
\text { - The top management team regularly discusses the strengths } \\
\text { and strategies of their competitors }\end{array}$ \\
\hline $\begin{array}{l}\text { Inter-functional } \\
\text { Coordination }\end{array}$ & $\begin{array}{l}\text { - make business decisions collectively irrespective of the } \\
\text { - infortment or functional areas } \\
\text { shared among all departments } \\
\text { - all business functions are integrated to serve for the } \\
\text { customers } \\
\text { - managers have understood that everyone has a capacity in the } \\
\text { process of creating customer value }\end{array}$ \\
\hline Business Performances & - Average Annual Sales Growth Rate (AASG) \\
\hline
\end{tabular}

The data were collected from the hotels in ancient cities (as classified in Tourism Development Authority in Sri Lanka -SLTDA) covering Anuradhapura, Polonnaruwa, Sigiriya, Dambulla, Habarana, Kandy and Kurunegala in Sri Lanka. All 44 hotels in ancient cities approved by SLTDA were selected (one hotel did not respond). There were 26 classified hotels and 17 unclassified hotels in the study area. Primary data were collected through a self administered questionnaire and interviews and secondary data were collected from annual reports of United Nations World Tourism Organization (UNWTO), SLTDA, 
World Bank, Asia Development Bank (ADB) etc. The three components of the MO were measured using the MKTOR scale developed by Nerver and Slater in 1990. Data were collected to observe the different dimensions identified in the study covering the period from 2007 to 2009. Cronbach Alpha was used as a tool of testing reliability of 14 scale data, which resulted in an Alpha value of 0.926. Both descriptive and inferential statistics were used to analyze data.

\section{RESULTS AND DISCUSSION}

\section{Business strategy and market orientation}

The dominant business strategy of hotels in ancient cities of Sri Lanka is presented in Table 2. One of the main findings of the study was that the majority of hotels were giving the first priority to offer services at lower prices than that of competitors - Group $1(53 \%)$. Other strategies namely experimenting new service concepts $(7 \%)$, adopting services of the competitors (7\%), the quality aspects of the services (19\%), and offering a faster service $(14 \%)$ were given less priority. The hotels whose business strategy was to offer services at lower prices were very conscious of reducing the cost of services and to attract more customers by offering the services at a lower price than their competitors. In these hotels the prices of rooms and food and beverage were comparatively lower than the hotels in other categories. The observable fact was that, many hotels in this category had reduced the cost to a greater level at the expense of the service quality.

\section{Table 2. Dominant business strategy of hotels in ancient cities of Sri Lanka}

\begin{tabular}{clc}
\hline Group No. & \multicolumn{1}{c}{ Strategy Prioritization } & Percentage \\
\hline 1 & $\begin{array}{l}\text { Offer lower prices on comparable products/ services of } \\
\text { competitors }\end{array}$ & 53 \\
2 & $\begin{array}{l}\text { Offer higher quality products/ services than } \\
\text { competitors }\end{array}$ & 19 \\
3 & $\begin{array}{l}\text { Offer quick products/ services } \\
4\end{array}$ & $\begin{array}{l}\text { Introduce new products/ services ahead of competitors } \\
5\end{array}$ \\
Imitating competitors & 7 \\
\hline
\end{tabular}

Although limited in number (19\% - 8 hotels) the next dominant business strategy observed was offering higher quality services for the customers (Group 2). Under this strategic approach, the main focus was on obtaining safety and quality standards, and had taken immense efforts of getting aligned with ISO standards like ISO 14001 (environmental management standard); ISO 10667-1:2011 (establishes requirements and guidance for the client working with the service provider to carry out the assessment of an individual, a group, or an organization for work-related purposes); ISO 13289:2011 (applies to activities that will include participants being taken into an open water environment); ISI 14489 (Safe delivery of adventurous activities); ISO/DIS 14785 (Tourist information offices-Information and reception services); and ISO/AWI 17679 (Wellness spa-Service requirements). These hotels had taken tiresome efforts for continuous improvement of services by different aspects. 
The third dominant type of strategy observed in the hotels was offering quick services for the customers - Group 3 (14\%). Their actions have been focused on offering the services they own in a quick manner, e.g. serving food and beverage, and attending to room services. The important factor observed was that quality perspective of services was not regarded as a decisive dimension under this strategic perspective. Just like in the first group of hotels these hotels too were keen on delivering the services quicker at the expense of the quality.

The remaining two strategic perspectives namely, imitating competitors (7\%) and offering innovative services for customers ahead of competitors $(7 \%)$ had been given limited attention by these hotels. The few hotels offering new services ahead of competitors (Group 4) had come up with novel service concepts. A lot of community based activities like visits of traditional villages, weekly fairs, and visits to traditional handicraft villages were common among hotels with this strategic orientation. They also had tried to introduce new recipes by using the local foods and medicinal herbs. They have also come up with brand new concepts of green initiatives. Even the old concepts like spa activities, they have tried to offer in a novel manner. Hotels whose strategic orientation was imitating competitors (Group 5) were just focusing on what the competitors are doing in the industry and coming up with almost the same service, without much modification, to respond to the competitive pressure. For example, most of the hotels within fifth group try to imitate the recipes by using local foods as their competitors.

The next phase of analysis deals with observing the differences of degree of $\mathrm{CuO}, \mathrm{CoO}$ and IfC of hotels in ancient cities of Sri Lanka on the basis of different types of business strategies. The descriptive statistics are presented in Table 3.

Table 3. Relationship between business strategies and market orientation

\begin{tabular}{lccc}
\hline & $\begin{array}{c}\text { Business Strategy } \\
\text { Group }\end{array}$ & Mean Score & Std. Deviation \\
\hline $\mathrm{CuO}$ & 1 & 2.26 & 0.43 \\
& 2 & 3.43 & 0.37 \\
& 3 & 3.01 & 0.84 \\
& 4 & 4.55 & 0.95 \\
& 5 & 1.20 & 0.46 \\
$\mathrm{CoO}$ & 1 & 4.22 & 0.59 \\
& 2 & 3.61 & 0.76 \\
& 3 & 3.41 & 0.66 \\
& 4 & 4.34 & 0.25 \\
$\mathrm{IfC}$ & 5 & 1.65 & 0.44 \\
& 1 & 2.41 & 1.38 \\
& 2 & 3.01 & 0.88 \\
& 3 & 3.03 & 0.99 \\
& 4 & 3.96 & 0.43 \\
& 5 & 1.44 & 0.92 \\
\hline
\end{tabular}

Hotels in the fourth group showed a greater level of $\mathrm{CuO}$ while the hotels within fifth group showed lowest degree of $\mathrm{CuO}$. Hotels in the fourth group had taken immense efforts to understand what the customer needs are exactly. Customer orientation was found to be a main business philosophy of these hotels. They were taking intensive efforts in measuring 
the customer satisfaction frequently by various ways. The most common mode was getting the degree of satisfaction via simple questionnaires before leaving the hotel. Some hotels were asking questions and even maintaining suggestion boxes and letters addressed directly to the top management aimed at obtaining feedback on quality of the existing services and getting ideas for incubating new types of services. Some hotels were using the appreciation words of customers to promote themselves to attract more customers by maintaining an online publication of those statements. There were hotels even using models like SERVQUAL, to measure the perceptual gaps between the quality of services perceived by the customers and the management (Parasuraman et al.,1990) and adapt necessary strategies to fill the perceptual gaps in meeting the satisfaction of customers. They had a strong likelihood to offer exactly what the customer needs. Even the suggestions of customers were taken into consideration in developing the new service concepts. For example a hotel has developed a menu on hatawariya (Asparagus) and the hotel had received the idea from a tourist suffering from diabetes who has learnt that the food is good for the disease after visiting a traditional village. This hotel mentioned that the menu is famous among senior people suffering from diabetes.

As in Table 3, $\mathrm{CoO}$ is very high in group four and one, although the norm had different meanings for the two groups according to the interviews. In group four, they have been so attentive towards the actions and strategies of competitors to predict them and come up with the new service concepts more attractive than competitors. For hotels in group one, the competitor orientation had been maintained to offer lower prices on comparable products/services of competitors.

Hotels in the fourth group had a higher degree of IfC than hotels in other groups while the hotels in group five had the lowest degree of IfC. It was found that hotels in the fourth group had arranged daily meetings with department heads to share their ideas and plans. They were willing to maintain a pool of ideas even from lower level employees irrespective of the specific functions that they were serving.

The results revealed that scores of market orientation (i.e. $\mathrm{CuO}, \mathrm{CoO}$, and IfC), of group four hotels, is higher compared to the rest of the hotels. The MANOVA test was conducted to explore whether the degrees of $\mathrm{CuO}, \mathrm{CoO}$, IfC of hotels differ with the different business strategies. According to the test, Pillai's trace $(p=.003)$ reached the criterion for significance of 0.05 . Hence, the findings revealed that degree of $\mathrm{CuO}, \mathrm{CoO}$, and IfC within the hotels differ significantly with the different types of business strategies of hotels in the ancient cities of Sri Lanka. The business strategy of offering new services ahead of competitors have led them to focus more on customers, competitors, and coordination between departments, rewarding them with innovations new to the industry as well as the firm.

Table 4. Relationship between business strategy, market orientation, innovations and business performance

\begin{tabular}{lccccc}
\hline $\begin{array}{c}\text { Business } \\
\text { Strategy }\end{array}$ & CuO & $\begin{array}{c}\text { MO Mean Score } \\
\text { CoO }\end{array}$ & IfC & $\begin{array}{c}\text { No. of } \\
\text { Innovations }\end{array}$ & $\begin{array}{c}\text { Sales Growth } \\
\text { (\%) }\end{array}$ \\
\hline Group 1 & 2.26 & 4.22 & 2.41 & 4 & 3.47 \\
Group 2 & 3.43 & 3.61 & 3.01 & 8 & 8.87 \\
Group 3 & 3.01 & 3.41 & 3.03 & 5 & 5.83 \\
Group 4 & 4.55 & 4.34 & 3.96 & 10 & 13.33 \\
Group 5 & 1.20 & 1.65 & 1.44 & 1 & 1.33 \\
\hline
\end{tabular}


The most appealing observation is that hotels in group four are maintaining the highest degree of market orientation (MO).Hotels in this group maintain higher degrees of $\mathrm{CuO}$, $\mathrm{CoO}$ and IfC compared to other groups. Further, they generate the highest number of innovations and maintain the highest rate of sales growth while hotels in group five maintain the least in all above performance indicators explored within the study scope (Table 4).

\section{Market orientation and sales growth}

The correlation analysis performed to observe the relationship of $\mathrm{CuO}, \mathrm{CoO}$, and IfC with AASG resulted correlation coefficients of $0.86,0.79$, and 0.68 respectively all having probability values of less than 0.01 . Accordingly high positive relationships can be seen between $\mathrm{CuO}, \mathrm{CoO}$, and IfC and AASG. A composite variable was formed for market orientation by combining $\mathrm{CuO}, \mathrm{CoO}$, and IfC. Then a simple linear regression was performed to see the relationship between market orientation (MO) and sales performance (AASG). The correlation coefficient was $0.78(\mathrm{P}=0.001)$ and the result depicted that there is a strong positive correlation between market orientation and sales performances. The gradient of the regression line was 0.98 and it illustrated that if the market orientation is increased by one unit, the AASG would be increased by 0.98 . The $\mathrm{R}^{2}$ of 0.61 depicts that $61 \%$ of the variation in AASG can be explained by the market orientation. Hence, it was accepted that market orientation significantly predicts the sales growth of hotels in ancient cities of Sri Lanka.

\section{CONCLUSIONS}

The strategic priority of the majority of hotels in ancient cities of Sri Lanka has been to offer services at lower prices than the competitors. The main reason for majority of hotels to fall into this strategic approach may be due to the spending capacity of tourists coming to Sri Lanka when the research was conducted. Tourists with low spending capacity are attracted to Sri Lanka as it is in a transitional era of changing its image. Due to the war, most of the tourists did not come to Sri Lanka to visit Sri Lanka per se, may be they had the need to spend a cheap holiday at a tropical country. The country's strategies are strongly focusing on rebuilding the image of the country and this strategic orientation is a major obstacle for the strategic goals of the country. This trend should be changed within next coming years as the country is planning of giving up the mass tourism and promoting the niche tourism or special interest tourism.

Formulating innovation oriented business strategies could enhance the degree of customer orientation, competitor orientations and inter-functional coordination in the hotels, resulting in more innovative services leading to better sales growth. So, it is high time for the majority of hotels to deviate from low cost orientated strategic perspective and be growth and innovative oriented. The industry needs a bold strategic shift in catering for the increasing demand of tourism boom and get better rewards for the firm as well as the country. 


\section{REFERENCES}

Berthon, P., Hulbert J.M., and Pitt, L.F. (1999). To serve or create? Strategic orientations towards customers and innovation. Califonia Publication, pp.37-58.

Central Bank of Sri Lanka (2011), Annual Statistical Report - 2010, Central Bank of Sri Lanka, Colombo.

Deshpande, R., and Farley, J.U. (2000). Market-focused organizational transformation in China. Journal of Global Finance and Marketing. 32, 7-35.

Deshpande, R., Farley J.U., and Webster Jr F. (1993). Corporate culture, customer orientation, and innovativeness in Japanese firms: a quadrad analysis. Journal of Marketing. $57,23-37$

Gabel, T.G. (1995), Market orientation: theoretical and methodological concerns, Proceedings of the journal of American Marketing. 32, 243-264.

Gatignon, H., Xuereb, J.M. (1997). Strategic orientation of the firm and new product performance. Journal of Marketing. 34, 77-90.

Ginsberg, A., and Venkataman, N. (1985). Contingency perspectives of organizational strategy: a critical review of the empirical research. Academy Management Review.10, 42134.

Han, J.K., Namwoon, Srivastava, and Rajendra, K. (1998). Market Orientation and Organizational Performance: Is Innovation a Missing Link?. Journal of Marketing. 62, 30-45.

Homburg, C., Hoyer, W.D., and Fassnacht, M. (2002). Service orientation of a retailer's business strategy: dimensions, antecedents, and performance outcomes. Journal of Marketing. 72, 86-101.

Kohli, A.K. and Jaworsky, B.J. (1990) "Market Orientation: The Construct, Research Propositions, and Managerial Implications", Journal of Marketing, vol. 54, pp. 1-8

Kotler, P. (2003). Marketing Management, Prentice Hall, Upper Saddle River.

Laferty, B.A. and Hult, G.T.M. (2001). A synthesis of contemporary market orientation perspectives. European Journal of Marketing. 12, 92-109.

Narver, J.C. and Slater S.F. (1994). The Effect of Market Orientation on Business Profitability. Journal of Marketing. 4, 20-36.

Parasuraman, A., Zithmal, V.A. and Berry L.L. (1990). SERVQUAL: A multiple item scale for measuring customer perception, Journal of Retailing. 64, 12-40.

RAM Ratings (Lanka) Lt, Annual Report on the Hotel Sector 2011, Colombo.

Shapiro, B.P. (1988) "What the hell is 'Market Oriented"?", Harvard Business Review, Vol.66, 119-125 
Sri Lanka Tourism Development Authority, Annual Statistical Report 2010, Sri Lanka Tourism Development Authority, Colombo.

Sri Lanka Tourism Development Authority 2009/2010, [Accessed on 8.5.2011, 20.05.2010]. Available at Error! Hyperlink reference not valid.

Wind, Y. and Robertson, T. (1983). Marketing strategy: new directions for theory and research. Journal of Marketing. 47, 12-25.

World Tourism Statistics and Trends 2008, 2009, 2010, 2011, [Accessed on 20.01.2011].

Available at http://www.unwto.org 